\title{
PENJUALAN DARING (ONLINE) MENGGUNAKAN E-COMMERCE PADA ROB'STaRS
}

\author{
Zulfian Bias ${ }^{1}$, Grace Gata², Yuliazmi ${ }^{3}$ \\ ${ }^{123}$ Fakultas Teknologi Informasi, Sistem Informasi, Universitas Budi Luhur, Jakarta, Indonesia \\ Email: ${ }^{1} 1512500149 @$ student.budiluhur.ac.id, 2* grace.gata@budiluhur.ac.id, ${ }^{3}$ yuliazmi@ budiluhur.ac.id
}

\begin{abstract}
Abstrak-Rob'STaR's adalah pelaku usaha yang menjual model kaos berbagai warna dan ukuran untuk kalangan usia remaja hingga usia dewasa. Permasalahan yang terjadi yaitu pelanggan harus menanyakan tentang ketersediaan stock pada product karena penjual tidak mencantumkannya. Dengan dibuatnya sebuah website e-commerce ini diharapkan dapat membantu memecahkan masalah yang ada pada Toko tersebut. Serta dapat memberikan manfaat atau kemudahan bagi Rob'STaR'S dan pelanggan pada saat melakukan pemesanan dan pembayaran. Peneliti mengimplementasikannya dengan menggunakan Content Management System (CMS) Wordpress. Sedangkan metode yang digunakan untuk menganalisa yaitu Business Model Canvas (BMC). Hasil dari pembuatan e-commerce ini yaitu pelanggan tidak perlu lagi bertanya tentang ketersediaan stock pada product karena sudah di tampilkan pada website, serta dapat memudahkan admin pada saat membuat laporan perbulannya. Penulis berharap dengan dibuatnya website e-commerce bisa untuk mempermudah penjualan serta meningkatkan penjulan product, dapat membantu Rob'STaR's dalam mengatasi masalah-masalah yang sering terjadi saat ini. Agar terhindar dari kerusakan data atau kehilangan data disarankan untuk melakukan backup data secara rutin.
\end{abstract}

Kata Kunci: Penjualan, E-Commerce, CMS, BMC, WordPress

\begin{abstract}
Rob'STaR's is a business that sells T-shirts of various colors and sizes for teenagers to adulthood. The problem that occurs is that customers have to ask about the availability of stock on the product because the seller does not list it. With the creation of an e-commerce website is expected to help solve the problems that exist in the Store. It can also provide benefits or convenience for Rob'STaR'S and customers at the time of booking and payment. Researchers implemented it using Wordpress's Content Management System (CMS). While the method used to analyze is Business Model Canvas (BMC). The result of making this e-commerce is that customers no longer need to ask about the availability of stock on the product because it has been displayed on the website, and can facilitate the admin when making his monthly report. The author hopes that the creation of an e-commerce website can facilitate sales and increase product sales, can help Rob'STaR's in addressing the problems that often occur today. In order to avoid data damage or data loss it is recommended to back up data regularly
\end{abstract}

Keywords: Sales, E-Commerce, CMS, BMC, WordPress

\section{PENDAhULUAN}

Perkembangan Teknologi Informasi yang berkembang dengan sangat cepat seiring dengan kebutuhan manusia yang terus bertambah, membuat teknologi memiliki peran yang sangat penting akan kehidupan manusia. Untuk mengikuti perkembangan zaman, manusia saat ini dituntut untuk mengikuti perkembangan teknologi yang akan terus berkembang dari masa ke masa, jika manusia tidak mengikuti perkembangan teknologi maka dapat dipastikan akan menjadi masyarakat terbelakang. Dengan semakin berkembangnya teknologi mendorong berkembangnya ECommerce merupakan kegiatan pembelian, penjualan, dan pemasaran barang yang dilakukan melalui sistem elektronik, seperti melalui internet, televisi, dan jaringan komputer. Kemudahan yang didapat dalam melakukan transaksi akan memberikan pengaruh kepuasan dan pembelian berulang [1]. Bisnis mengunakan model e-commerce saat ini merupakan pilihan yang baik bagi para pengusaha yang ingin melakukan peningkatan penjualan [2].

Rob'STar'S merupakan wirausaha kecil yang bergerak dalam bidang penjualan baju dan kaos.Rob'STar'S ingin selalu memenuhi kebutuhan pelanggan.Rob'STar'S dalam keberlangsungannya masih memiliki masalah dalam membuat promosi dimana media yang digunakan hanya Instagram sehingga product yang dijual tidak mencakup jangkauan yang luas untuk calon pelanggannya dan berharap Rob'STar'S dapat bersaing dengan penjual online lainnya karena selama ini penjualan hanya sebatas media tertentu. Untuk itulah, penulis mencoba untuk merancang website penjualan berbasis E-Commerce dengan memanfaatkan teknologi internet dan komputer sebagai media pemasaran dan penjualan online dimana data dapat tersimpan dengan baik dan pelanggan dapat berinteraksi serta berperan aktif dalam proses jual beli sehingga diharapkan Rob'STar'S dapat memperoleh keuntungan yang maksimal melalui teknologi internet, dengan mengandalkan jumlah pengguna internet yang semakin meningkat setiap tahun [3].

Berdasarkan analisis yang dilakukan, maka ditemukan beberapa masalah yang dihadapi oleh Rob'STaR'S. Adapun masalah-masalah yang kerap dihadapi adalah sebagai berikut: Promosi yang tidak memiliki jangkauan luas mengakibatkan sepinya konsumen, Kalah bersaing dengan penjual yang sudah mempunyai E-Commerce tersendiri, Pelanggan akan bertanya dahulu ketersediaan stock jika membeli salah satu product, Banyak Product tidak laku terjual sehingga banyak barang yang menumpuk di gudang. Adapun tujuan yang hendak dicapai adalah mempermudah 
penyajian informasi yang dibutuhkan baik oleh konsumen maupun pemilik toko, Memudahkan pelanggan dalam memilih stock pada product, Membuatkan website e-commerce dengan harapan dapat meningkatkan penjualan product. Manfaat yang diharapkan dapat meningkatkan penjualan pada toko dan mempromosikan lebih luas barang yang akan dijual serta mengefisienkan pembuatan laporan penjualan toko.

Dalam penelitian sebelumnya yang membuat sebuah aplikasi penjualan berbasis web yang memanfaatkan ECommerce untuk menunjang pengoptimalan tingkat penjualan di toko Distro Mr Bro. Aplikasi yang dipergunakan yaitu woocommerce sebagai tempat untuk menampilkan barang dan melakukan transaksi online. Metode yang digunakan yaitu metode Business Model Canvas (BMC) bertujuan agar dapat menyusun strategi untuk membuat tokonya telihat berbeda dari pesaingnya dan dapat mengambil langkah untuk mencapai tujuan bisnisnya dan menerapkan metode Interaction Flow Modelling Language (IFML) untuk mendukung interaksi pengguna dan mengatur perilaku dari front-end website e-commerce yang dibuat [4].

Penelitian lain yang membahas mengenai penggunaan E-Commerce sebagai penyebaran informasi tentang produk pada Gepard Motoshop melalui E-Commerce menjadi lebih luas dan promosi menjadi lebih efektif untuk Gepard Motoshop merupakan suatu unit usaha yang bergerak dibidang service dan penjualan perlengkapan sepeda motor. Permasalahan yang dihadapi Gepard Motoshop yaitu kesulitan dalam mengetahui informasi pemesanan dari pelanggan karena pemesanan hanya mengandalkan sosial media seperti instragram dan whatsapp, belum mempunyai media media untuk merekam pesanan pelanggan dalam prosesnya dapat menghambat dalam proses penjualan. Metode penelitian ini mempergunakan Bussines Model Canvas, Activity Diagram, Use Case, Interaction Flow Modeling Language, Class Diagram dan System Sequence Diagram [5].

\section{METODE PENELITIAN}

Metode penelitian adalah suatu tata cara bagaimana suatu penelitian dilaksanakan [6]. Pengertian lain dari metode penelitian ialah cara yang digunakan oleh peneliti dalam mengumpulkan data penelitiannya, seperti wawancara, observasi, tes maupun dokumentasi dari bisnis yang dilakukan [7], sedangkan metode penelitian merupakan suatu cara untuk memperoleh kembali solusi terhadap segala permasalahan [8].

\subsection{Kerangka Pemikiran}

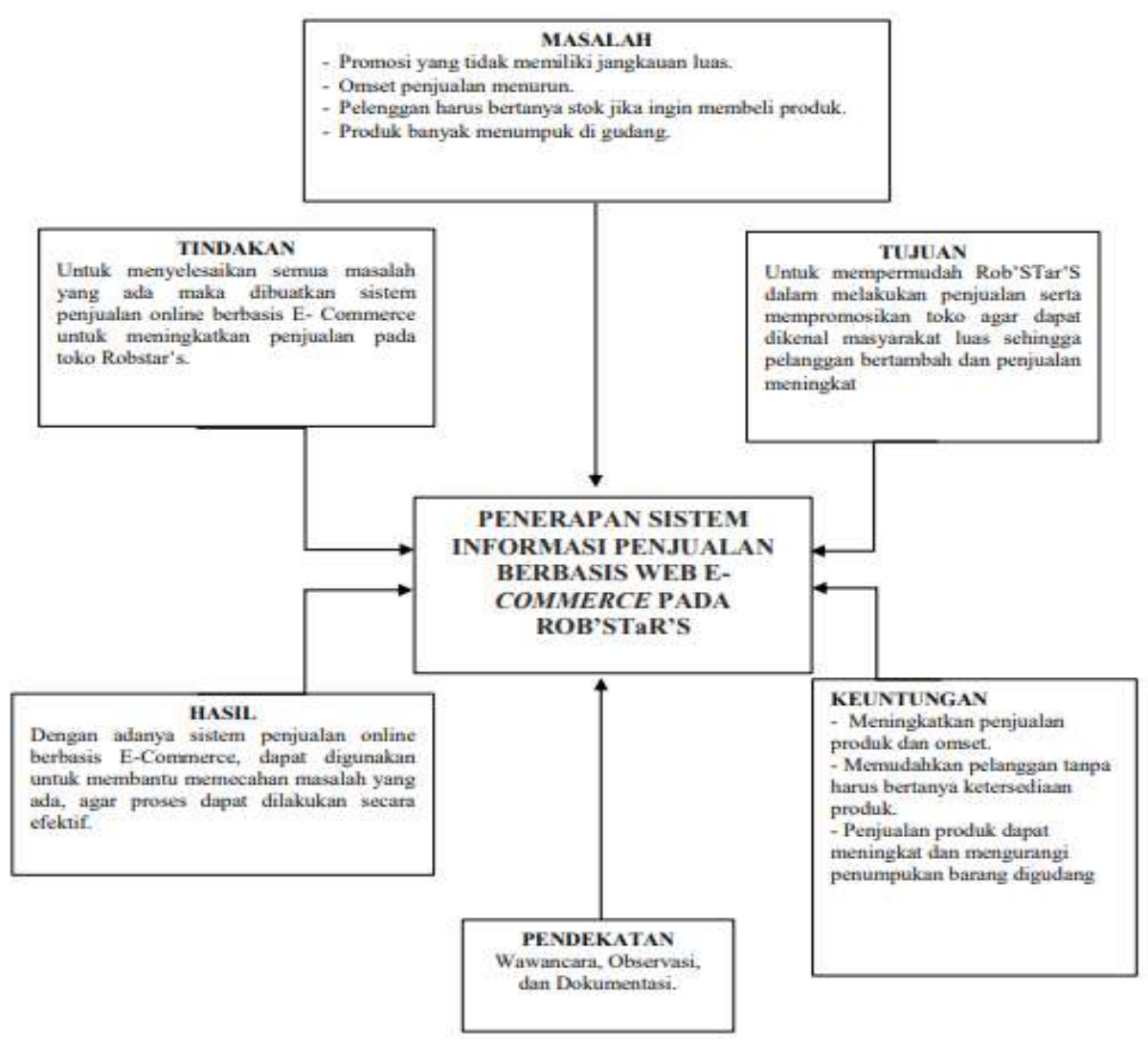

Gambar 1. Kerangka Pemikiran 
Untuk mempermudah Rob'STar'S dalam melakukan penjualan serta mempromosikan toko agar dapat dikenal masyarakat luas sehingga pelanggan bertambah dan penjualan meningkat, melakukan pendekatan dengan cara melakukan wawancara, observasi, dan dokumentasi. Keuntungan yang didapat adalah meningkatkan penjualan produk dan omset, Memudahkan pelanggan tanpa harus bertanya ketersediaan produk, Penjualan produk dapat meningkat dan mengurangi penumpukan barang digudang. Selanjutnya tindakan dalam menyelesaikan semua masalah yang ada maka dibuatkan sistem penjualan online berbasis E- Commerce dengan menggunakan CMS Wordpress sebagai CMS yang paling sering digunakan untuk meningkatkan penjualan online [9]. Dengan adanya sistem penjualan online berbasis E-Commerce, dapat digunakan untuk membantu memecahan masalah yang ada, agar proses dapat dilakukan secara efektif. Sehingga masalah yang dihadapi seperti: Promosi yang tidak memiliki jangkauan luas, Omset penjualan menurun, Pelanggan harus bertanya stok jika ingin membeli produk, Produk banyak menumpuk di gudang. Seperti yang terlihat pada Gambar 1.

\subsection{Metode Pengumpulan Data}

Dalam menyelesaikan penelitian ini metode yang digunakan yaitu: Observasi, wawancara, dokumentasi dan studi pustaka, dalam melakukan observasi mengumpulkan data dengan cara mengamati proses penjualan yang terjadi sehingga mendapatkan data yang jelas dan lengkap. Wawancara dilakukan secara langsung kepada pemilik toko mengenai alur proses bisnis penjualan yang terjadi secara rutin di toko Rob'Star'S.

Dilanjutkan dengan pengumpulan data dengan mencari informasi berdasarkan dokumen-dokumen berjalan sesuai dengan kebutuhan sistem, serta melakukan studi pustaka melalui jurnal dan buku yang ada di internet, serta melalui rujukan buku yang membahas hal yang sama.

\subsection{Metodologi Analisis dan Penggunaan Tools}

Analisis yang dilakukan terdiri dari Analisis proses bisnis, Analisis masalah dan Analisis perancangan sistem, dalam Analisis Proses Bisnis dilakukan dengan menguraikan bisnis kemudian dibuat menjadi Activity Diagram. Di dalam Activity Diagram ini menggambarkan proses bisnis pada Rob'STar'S. Untuk Analisis Masalah dilakukan dengan observasi dan wawancara guna mengetahui permasalahan yang ada, sehingga dapat diuraikan sebab dan akibat dari masalah yang ada pada Rob'STar'S. Berikutnya Analisis Perancangan Sistem didapat berdasarkan hasil dari analisis yang didapat pada Rob'STar'S, Permasalahan yang ada dapat dibuatkan sebuah solusi dengan kebutuhan apa saja yang dibutuhkan dan dipaparkan melalui gambar yang dibuat menggunakan Activity Diagram dan Use Case Diagram. Analisis model bisnis yang dilakukan menggunakan Business Model Canvas dimana menggambarkan bagaimana organisasi menciptakan manfaat dan mendapatkan manfaat bagi dan dari pelanggannya.

\section{HASIL DAN PEMBAHASAN}

\subsection{Business Model Canvas (BMC)}

BMC merupakan perumusan konsep bisnis yang lebih sederhana dibandingkan dengan membuat rencana bisnis yang sudah biasa dilakukan, cara sederhana ini untuk mempresentasikan elemen penting yang terdapat pada sebuah model bisnis. BMC disajikan berupa suatu kanvas yang terdiri dari 9 kotak yang saling berkaitan. Kerangka model bisnis yang berbentuk kanvas dan terdiri dari sembilan blok yang berisikan elemen-elemen yang saling berkaitan Berikut merupakan gambaran sembilan elemen Business Model Canvas, terdiri dari: Key Partners, Key Activities, Key Resources, Value Propositions, Customer Relationships, Customer Segments, Cost Structure [10].

Dalam bisnis model kanvas memiliki 9 area dari model bisnis yang sangat diperlukan dalam menjalankan suatu usaha. Berikut ini adalah penjelasan-penjelasan tentang Business Model Canvas seperti yang terlihat pada Gambar 2 sebagai berikut:

a. Key Partners, Supaya bisnis dapat berjalan dengan baik Rob'star's melakukan kerja sama dengan beberapa distributor baju atau kaos, bank, dan jasa ekspedisi.

b. Key Activities, Kegiatan utama yang dilakukan oleh Rob'star's yaitu melakukan penjualan kaos atau baju.

c. Value Propositions, Nilai yang ditawarkan oleh Rob'star's adalah di setiap weekend memberikan diskon $20 \%$ untuk semua product yang tersedia dan product yang dijual dari brand ternama, bebas ongkos kirim dan harga yang bersaing serta pelayanan cepat.

d. Customer Relationships, Cara Rob'star's mempertahankan pelanggan untuk tetap membeli product yaitu dengan cara memberikan informasiinformasi mengenai promo-promo yang sedang berlangsung melalui instagram dan website. Serta Rob'star's memberikan giveaway pada setiap akhir bulan melalui instagram, di harapkan pelanggan akan terus membeli product di Rob'star's. 
e. Customer Segments, Banyak pelanggan dari Rob'star's yaitu laki-laki dan perempuan berusia 17-35 tahun karena product yang ditawarkan oleh Rob'star's ditunjukkan untuk anak-anak muda seperti siswa/siswi, mahasiswa/mahasiswi serta orang-orang yang sudah berpenghasilan.

f. Key Resources, Supaya bisnis dapat berjalan dengan baik, Rob'star's membutuhkan hal penting yang harus kita punya agar dapat menjalankan key activities dan value yang dapat diberikan pada pelanggan yaitu handhaphone, laptop dan Internet.

g. Channels, Setelah mengetahui calon pelanggan yang dituju, Rob'star's kedepannya akan menggunakan instagram sebagai media pemasaran digital yang utama dan website e-commerce sebagai 23 media pemasaran sekaligus penjualan yang baru serta WhatsApp dan Live chat sebagai media komunikasi antara Rob'star's dengan pelanggan.

h. Cost Structure, Biaya operasional yang dikeluarkan Rob'star's yaitu peralatan foto product, kemasan dan packaging, biaya internet bulanan serta biaya hosting dan domain pertahun.

i. Revenue Streams, Sebagai pelaku usaha, pendapatan merupakan hal yang sangat penting dalam menjalankan sebuah usaha dimana pendapatan ini sangat berpengaruh terhadap bisnis yang sedang dijalankan. Untuk itu Rob'star's telah memikirkan produk apa yang dapat diandalkan sebagai sumber pendapatan yaitu penjualan kaos.

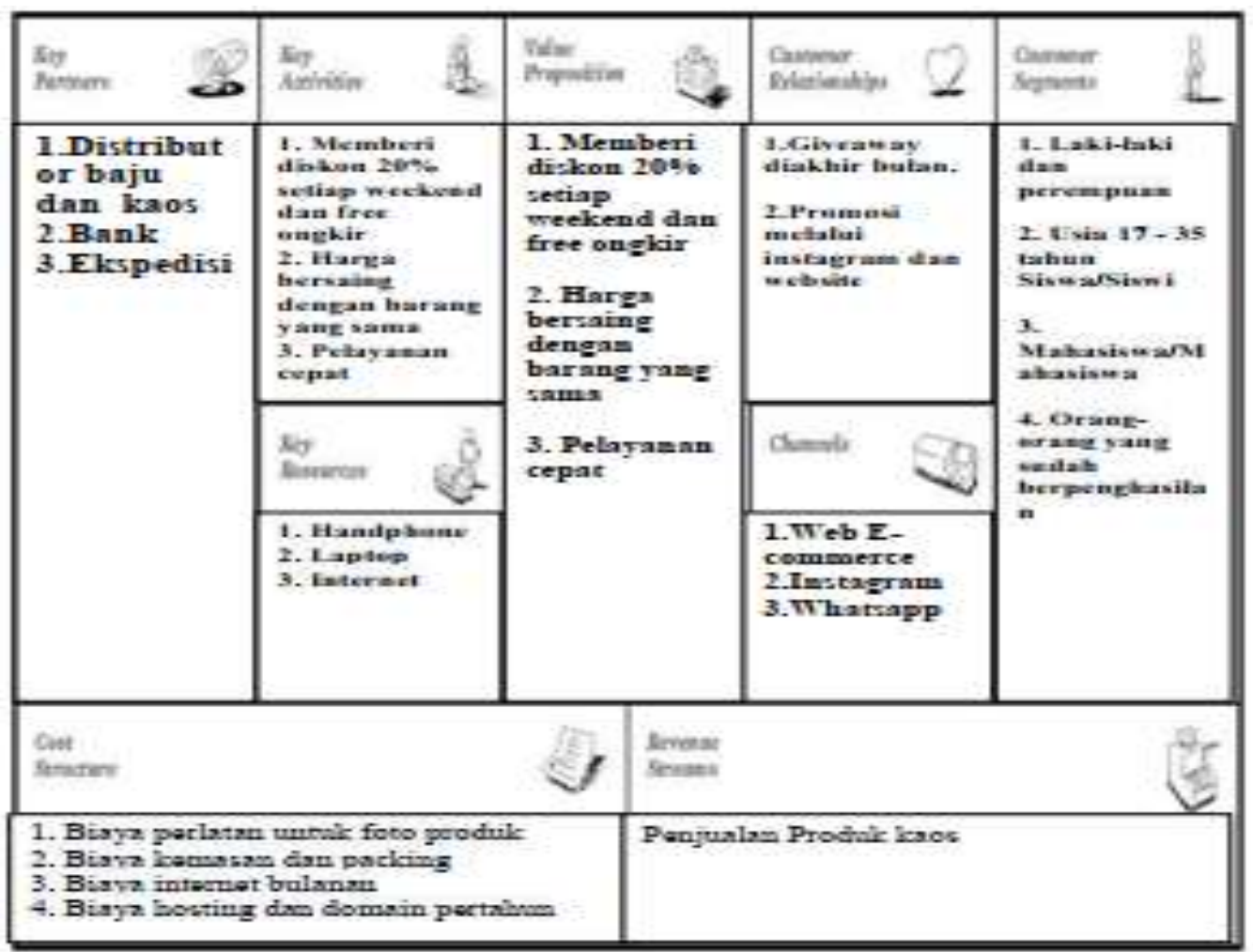

Gambar 2. Business Model Canvas

\subsection{Proses Bisnis Usulan}

\section{a. Proses Entry Product}

Pada proses ini Admin melakukan login terlebih dahulu, setelah itu sistem menampilkan backend website. Admin memilih menu product. Lalu memilih sub menu add new. Pada halaman add new, admin mengisi form berupa nama product, deskripsi product, harga product, variasi product, kategori product, gambar product. Setelah itu admin mempublish product. Lalu sistem menampilkan product yang sudah ditambahkan di halaman front-end website robstarcollection.com. Seperti yang terlihat pada Gambar. 3. 
Halaman 63-72

Available online at http://jom.fti.budiluhur.ac.id/index.php/IDEALIS/index

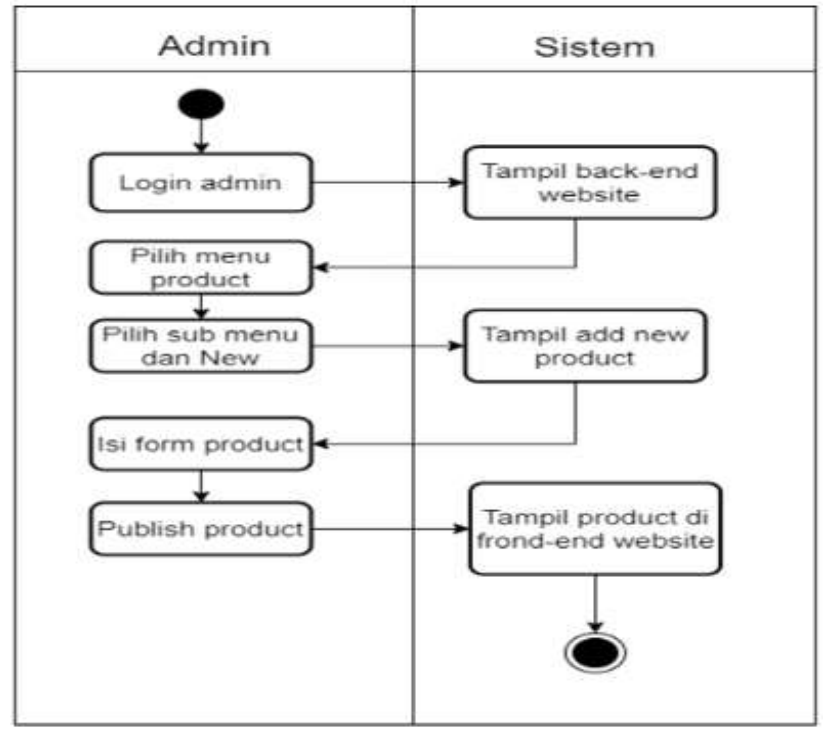

Gambar 3. Activity Diagram Entry Product

\section{b. Proses Register Pelanggan dan Login Pelanggan}

Pelanggan yang akan membeli product diwajibkan untuk melakukan register. Pelanggan masuk kehalaman website, lalu memilih menu my account. Setelah itu mengisi data pelanggan dan mengklik tombol register. Sistem akan menyimpan data pelanggan dan pelanggan akan mendapatkan $e$-mail notifikasi.

Pelanggan yang sudah memiliki akun, dapat langsung login dengan memilih menu my account. Pelanggan menginput username dan password, lalu mengklik tombol login dan sistem akan mengeceknya apabila tidak valid maka sistem akan memberitahu bahwa username dan password salah. Apabila valid maka akan langsung masuk kehalaman my account. Seperti yang terlihat pada Gambar 4.
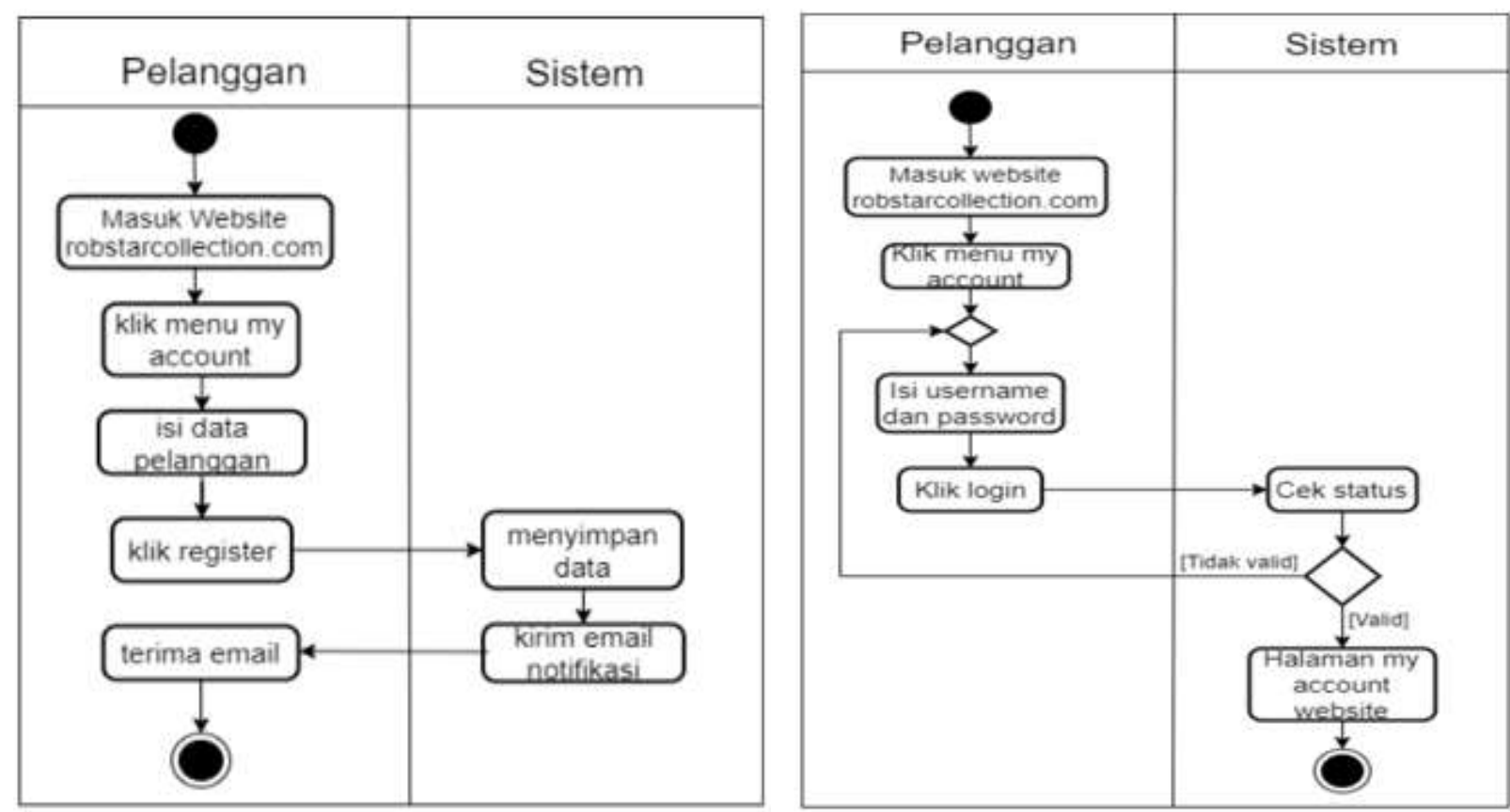

Gambar 4. Activity Diagram Proses Register Pelanggan dan Login Pelanggan 


\section{c. Proses Pemesanan}

Pelanggan masuk kehalaman website, memilih product di menu shop dan categories lalu melihat product yang akan dipesan dan pelanggan memilih size dan jumlah product. Pelanggan mengklik add to cart, setelah itu mengklik view cart selanjutnya mengklik proceed to checkout. Sistem akan mengecek apakah pelanggan sudah login atau belum. Jika belum login maka sistem akan memberitahu bahwa pelanggan harus login terlebih dahulu, pelanggan bisa ke menu my account terlebih dahulu dan mengisi form login, setela itu pelanggan bisa melakukan proses checkout. Apabila sudah login pelanggan mengisi data order dan muncul total yang harus dibayar beserta nomor rekening penjual, lalu mengklik place order, sistem akan menyimpan data order, kemudian pelanggan mendapatkan notifikasi e-mail.

Setelah pelanggan melakukan pemesanan product, pelanggan melakukan pembayaran berdasarkan bukti pemesanan yang telah dikirim oleh sistem. Pembayaran dilakukan dengan cara transfer sesuai berdasarkan bank yang tertera di bukti pemesanan. Setelah pelanggan melakukan pembayaran, pelanggan harus masuk ke website, kemudian pelanggan melakukan payment confirmation dengan mengisi form payment confirmation dan mengupload bukti transfer di menu payment confirmation jika sudah klik kirim, Setelah itu admin mengecek bukti pembayaran pelanggan pada menu caldera forms setelah itu admin memverifikasi pembayaran dan apabila pelanggan sudah transfer admin akan mengubah status pesanan dan admin memproses pesanan pengirim apabila dalam 1 kali 24 jam pelanggan tidak transfer maka admin akan membatalkan pesanan pelanggan, seperti yang terlihat pada gambar 5 .

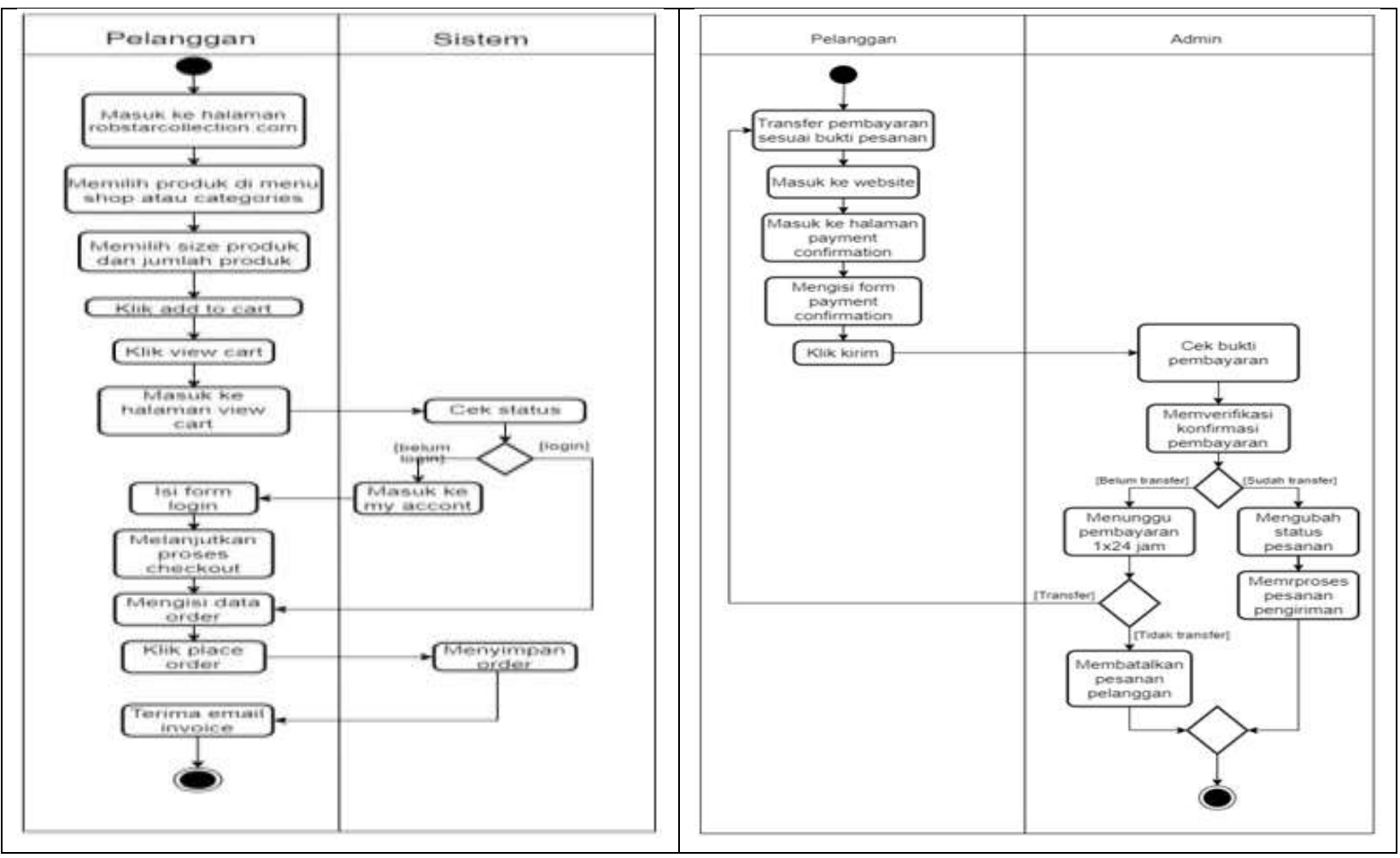

Gambar 5. Activity Diagram Proses Pemesanan dan Konfirmasi Pembayaran

\section{d. Proses Pengiriman}

Setelah pembayaran diterima, admin menyiapkan product sesuai pemesanan. Admin website masuk ke halaman back-end website Rob 'star's lalu memilih menu WooCommerce dan pilih menu orders. Pada halaman pesanan, admin mencetak packing slip (label shipping) untuk diberikan ke pada pihak ekspedisi, pihak ekspedisi menerima product dan membuatkan nomor resi, setelah itu pihak ekspedisi memberikan nomor resi kepada admin, kemudian admin mengirimkan notifikasi email yaitu berupa pengiriman telah dilakukan oleh pihak ekspedisi beserta nomor resinya kepada pelanggan. Pelanggan mendapatkan notifikasi $e$-mail bahwa pesanannya telah dikirim.

Untuk melakukan pengecekan status pemesanan, Pelanggan dapat mengakses website Rob 'star's, kemudian pelanggan melakukan login di halaman my account. Sistem akan mengecek form login yang dimasukan pelanggan valid atau tidak valid, jika valid maka login berhasil dan jika tidak valid maka pelanggan melakukan login ulang. Setelah login berhasil, pelanggan dapat melihat status pesanan dengan mengklik menu orders, seperti yang terlihat pada Gambar 6. 
Available online at http://jom.fti.budiluhur.ac.id/index.php/IDEALIS/index

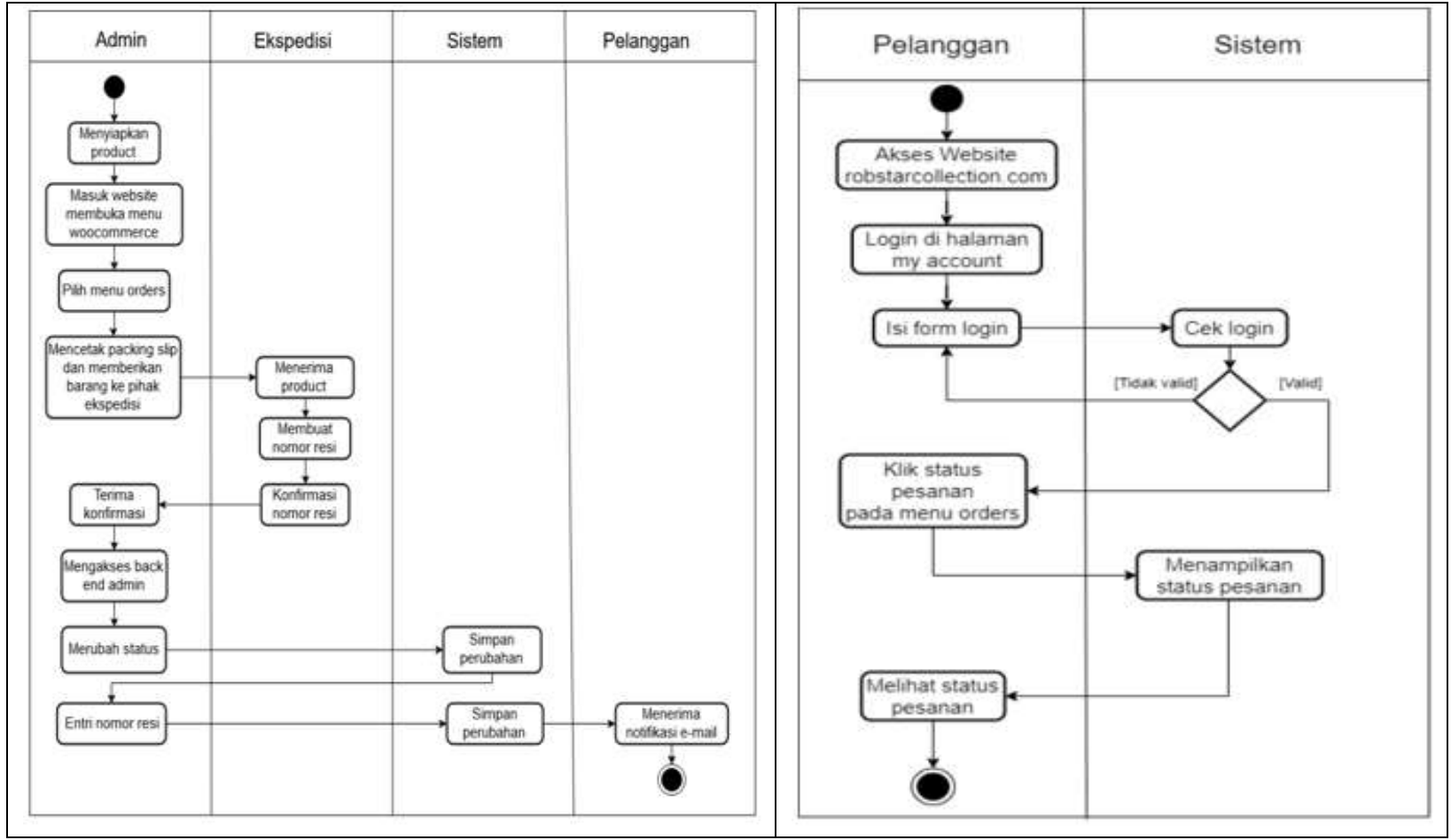

Gambar 6. Activity Diagram Proses Pengiriman dan Cek Status Pesanan

\section{e. Proses Refund}

Product telah diterima oleh pelanggan, apabila terdapat product yang tidak sesuai dengan pesanan maka pelanggan dapat melakukan refund dengan cara pelanggan mengakses website Rob 'star's lalu masuk ke menu refund kemudian pelanggan mengisi form refund jika sudah selesai klik kirim. Setelah selesai mengisi form, admin akan mengecek refund yang di input oleh pelanggan di menu caldera forms. Admin website akan memproses refund yang dilakukan pelanggan apabila memang terjadi kerusakan pada product dengan melihat bukti foto yang telah di upload oleh pelanggan dan pelanggan harus mengirimkan product yang ingin di refund ke Rob'star's jika product yang di beli rusak, setelah admin menerima product refund dari pelanggan maka uang akan segera di kembalikan, jika tidak terjadi kerusakan maka admin website membatalkan proses refund. Seperti yang terlihat pada Gambar 7.

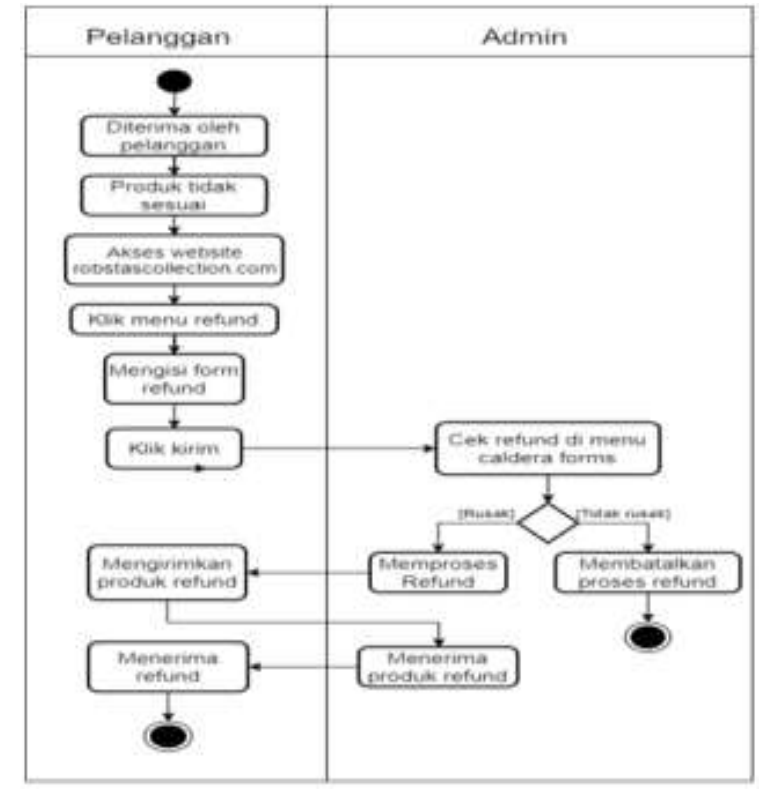

Gambar 7. Activity Diagram Proses Refund dan Pembuatan Laporan 


\section{f. Pembuatan Laporan}

Proses dalam pembuatan laporan, Admin harus login kehalaman backend, kemudian Admin memilih menu woocommerce export orders, admin mencetak report seperti report order, report sales, report shipping, report refund, report recapitulations best sellers product dan kemudian admin mencetak report tersebut. Seperti terlihat pada Gambar 8.

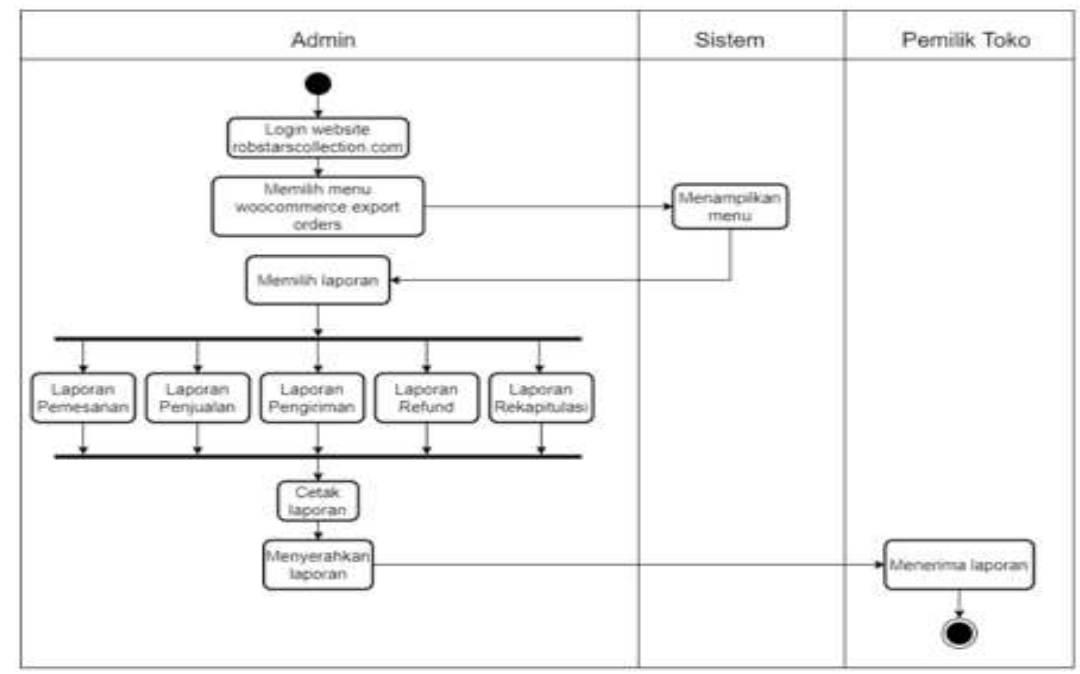

Gambar 8. Activity Diagram Proses Pembuatan Laporan

\subsection{Use Case Diagram}

Alur sistem yang Menjelaskan apasaja proses yang dikerjakan oleh user tergambar dalam Use Case Diagram berikut:

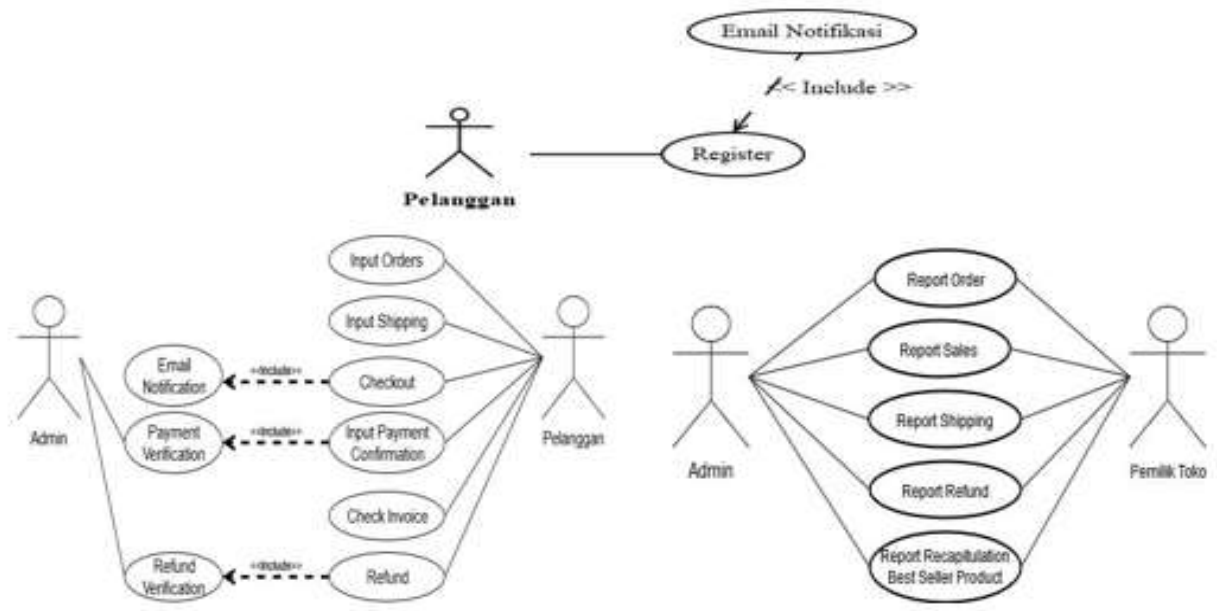

Gambar 9. Use Case Diagram

Pada Use Case Diagram Gambar 9. menjelaskan tentang alur pelanggan mendaftarkan akun pada website.Pelanggan belum memiliki akses login dan ingin mendaftar untuk melakukan pembelian product pada website. Pelanggan mengakses website Rob'star's dan masuk ke halaman my account. Pelanggan mengisi nama lengkap, username dan password. Jika sudah selesai, pelanggan mengklik tombol register maka data pelanggan akan tersimpan dan sistem akan mengirimkan notifikasi email. Post Condition: Pelanggan sudah mendaftarkan akun pada website serta pelanggan mendapat notifikasi email dan pelanggan sudah dapat login pada website.

Pelanggan mengakses halaman website dan menuju halaman shop atau categories untuk memilih atau memesan product. Setelah memilih product, pelanggan mengklik tombol add to cart maka product tersimpan ke dalam cart. Pelanggan dapat melakukan pemesanan kembali dengan cara kembali ke halaman shop. Pelanggan memilih kurir yang tersedia pada website. Pelanggan memilih kurir yang tersedia pada website. Kemudian akan tampil harga shipping dan kurir yang telah di pilih oleh pelanggan. Proses checkout yang dilakukan pelanggan. mengakses website 
dan masuk ke halaman checkout. System menampilkan review order yang di pesan dan pelanggan mengisi data diri. Seperti shipping atau alamat shipping serta memilih layanan kurir.Setelah mengisi data diri, pelanggan mengklik place order untuk menyimpan data shipping. Setelah pelanggan mengklik place order, pelangan akan mendapat email notification.Setelah pelanggan melakukan checkout, admin akan mengirimkan email notification melalui email. Admin akan mengirimkan email notification yang berisikan total jumlah pembayaran yang harus di bayarkan oleh pelanggan. Pelanggan melakukan payment confirmation. Setelah pelanggan melakukan checkout, admin akan mengirimkan email notification melalui email. Admin akan mengirimkan email notification. Pelanggan melihat invoice Pelanggan mengakses website dan masuk ke halaman my account Pelanggan mengisi username dan password lalu klik login Akan muncul halaman dashboard pelanggan jika pelanggan berhasil login. Pelanggan ingin melakukan refund tetapi belum mengupload bukti foto atau belum download invoice. Admin memverifikasi data pelanggan yang melakukan refund Jika data valid, admin mengubah status orders pelanggan menjadi refunded dengan masuk ke menu Kemudian admin mengklik tombol update, maka status orders pelanggan menjadi refunded.

Alur pembuatan report atau laporan Admin yaitu report order, report sales, report shipping, report refund dan repor recapitulation best sales product setiap bulannya yang akan diberikan kepada pemilik Toko Admin login pada halaman back-end website. Setelah admin berhasil login, admin memilih menu woocommerce dan mengklik menu report yang diinginkan. Admin membuat report yang nantinya akan diberikan kepada pemilik Rob'star's. Setelah dibuat, admin mengklik tombol export. Maka report yang telah dibuat akan tercetak dalam bentuk pdf.

\subsection{Rancangan Layar}

Rancangan layar dibuat untuk mempermudah pelanggan dalam melakukan belanja online dimulai dari tampilan Home yang menampilkan artikel, layar Shop menampilkan seluruh product yang ada di menu shop dan categories. Layar Orders menampilkan product tampilan menu ukuran, warna, jumlah dan add to cart pada rancangan layar orders menampilkan jumlah product yang ingin dipesan. Layar Cart menampilkan product yang dimasukan kedalaam cart. Pada rancangan layar cart menampilkan cart total sementara. Layar Checkout yang berisi data pelanggan seperti nama, alamat, email dan note. Pada rancangan layar checkout menampilkan total yang harus di bayar dan transfer bank. Layar Payment Confirmation menampilkan data pembayaran seperti nama, no.order, email, no.handphone, tanggal transfer, jumlah transfer, bank transfer, nama pemilik rekening dan bukti transfer, Layar Refund menampilkan data refund seperti nama, no.order, email, no.handphone, tanggal transfer, keluhan refund dan bukti refund. Layar Check Invoice menampilkan status invoice pada menu my account. Rancangan Layar Print Invoice menampilkan menu order, date, status, total dan actions, seperti yang terlihat pada Gambar 10.

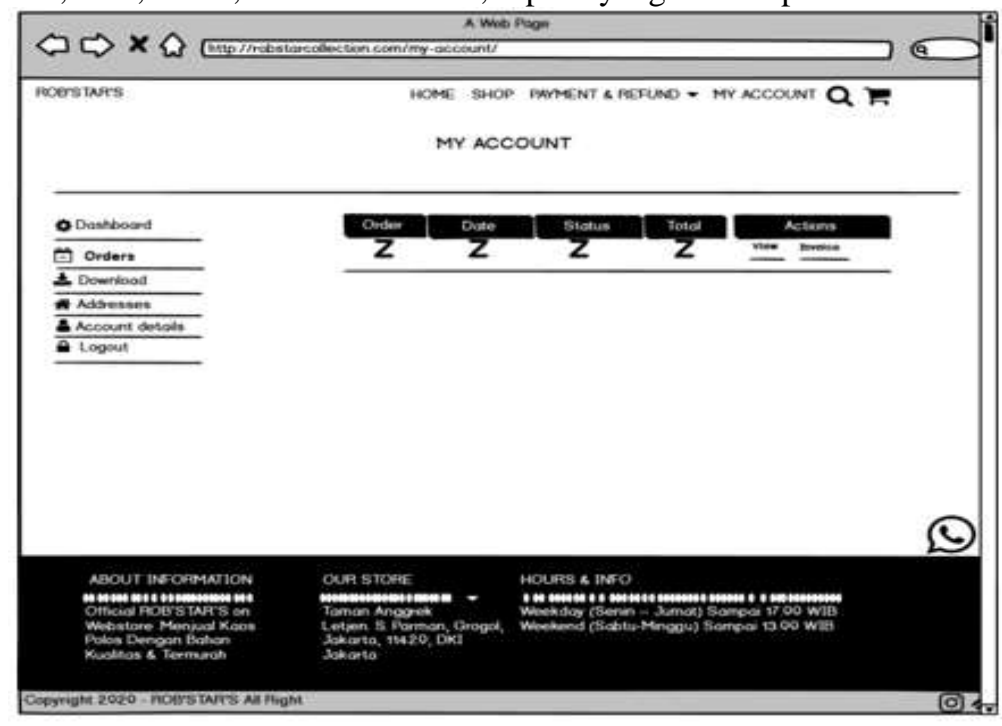

Gambar 10. Rancangan Layar Print Invoice

\subsection{Search Engine Optimization (SEO)}

Strategi SEO merupakan suatu cara agar sebuah website dapat di index oleh mesin pencari berdasarkan kata kunci yang dicari. SEO butuh analisa dan penempatan yang tepat serta persaingan, strategi, dan waktu adalah faktor yang mempengaruhi tingkat website pada mesin pencari, untuk meningkatkan volume dan trafik kunjungan [11]. Selain itu fungsi dari penggunaan SEO adalah sebagai media promosi untuk meningkatkan penjualan [12]. SEO On Page merupakan sebuah cara untuk mengoptimalkan halaman dan konten website agar dapat di index oleh mesin 
Available online at http://jom.fti.budiluhur.ac.id/index.php/IDEALIS/index

pencari dari dalam website itu sendiri. Rob'STarR's mengoptimalkan SEO On Page dengan pendekatan White-Hat SEO menggunakan plugins Yoast SEO dan mengatur isi konten pada halaman website. Pencarian kata kunci merupakan tahap awal dalam penerapan SEO On Page, kata kunci yang relevan dengan nama product yang dijual merupakan dasar dalam pencarian kata kunci. Keywords atau kata kunci merupakan sebuah kata atau kalimat yang disusun untuk mencari website atau informasi yang terdapat di internet. Kata kunci yang dipilih difokuskan pada main content website, dimana main content tersebut ada pada detail product atau informasi product yang dijual dan untuk setiap product yang ditampilkan harus selalu melakukan pencarian kata kunci. 11.

Adapun hasil penerapan SEO yang telah diterapkan pada website Rob'STaR'S seperti yang terlihat pada Gambar

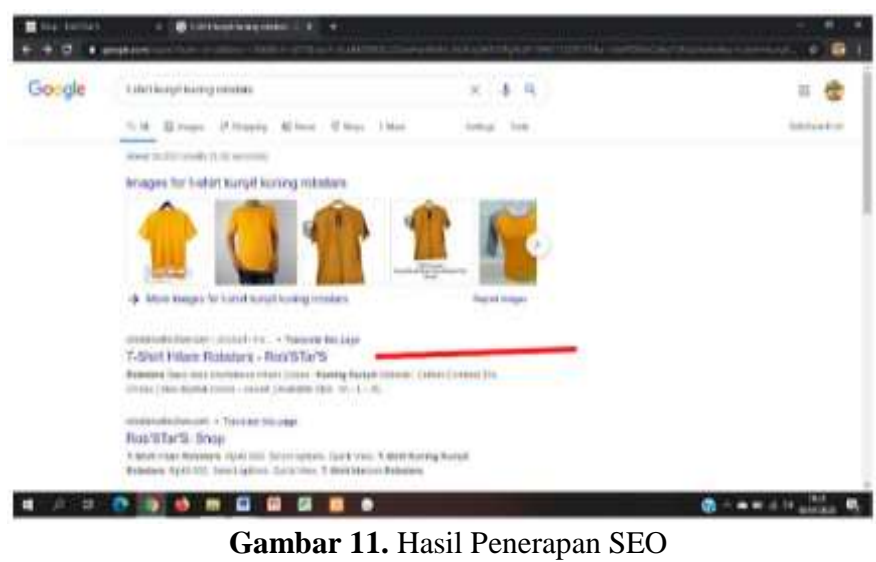

\section{KESIMPULAN}

Dari hasil pembahasan yang ada, maka menghasilkan beberapa kesimpulan sebagai berikut: Dengan adanya website e-commerce ini Rob'STar'S dapat lebih berkembang dalam proses penjualan. Fitur website e-commerce ini dapat membantu Rob'STar'S dalam mengecek laporan stok, sehingga dapat memperlancar saat proses penjualan. Menggunakan website e-commerce ini dapat mempermudah pemilik dalam mendapatkan laporan penjualan. serta dapat menyampaikan tentang informasi produk kepada pelanggan.

\section{DAFTAR PUSTAKA}

[1] M. E. Widiana, H. Supit, and S. Hartini, "Penggunaan Teknologi Internet dalam Sistem Penjualan Online untuk Meningkatkan Kepuasan dan Pembelian Berulang Produk Batik pada Usaha Kecil dan Menengah di Jawa Timur,” Jurnal Manajemen. dan Kewirausahaan, vol. 14, no. 1, pp. 71-81, 2012.

[2] S. M. Maulana, H. Susilo, and Riyadi, "Implementasi E-Commerce Sebagai Media Penjualan Online," Jurnal Administrasi Bisnis, vol. 29, no. 1, pp. 1-9, 2015.

[3] A. D. Riyanto and Purwadi, "Penerapan Teknik Search Engine Optimization (SEO) untuk Memenangkan Persaingan Kata Kunci pada Mesin Pencari Google," Jurnal Informatika, vol. IV, no. 2, pp. 59-65, 2016.

[4] T. dwi Alperdo and G. Gata, "Implementasi E-Commerce Menggunakan Business Model Canvas Dan Ifml Pada Distro Mr Bro," J u r n a l I D E A L I S, vol. 2, no. 6, pp. 369-376, 2019.

[5] S. Informasi et al., "E-Commerce Untuk Meningkatkan Penjualan Perlengkapan Sepeda Motor pada Gepard Motoshop," IDEALIS, vol. 2, pp. 34-41, 2019.

[6] M. I. Hasan, Pokok-pokok Materi Statistika 1 (Statistik Deskriptif), Edisi Kedu. Jakarta: PT. Bumi Aksara, 2002.

[7] S. Arikunto, Prosedur Penelitian - Suatu Pendekatan Praktek, Cetakan Ke. Jakarta: PT. Rineka Cipta, 2002.

[8] S. Ahmad, Marketing In Business, Edisi pert. Jakarta: Mitra Wacana Media, 2010.

[9] A. Q. A. Dwi, "Pembuatan Website Menggunakan Cms Wordpress," Jurnal Aplikasi Bisnis, vol. 3, pp. 287-292, 2017.

[10] P. Osterwalder, Alexander and Yves, Business Model Generation. Jakarta: PT Elex Media Komputindo, 2012.

[11] A. Himawan, Arisantoso, "Search Engine Optimization (Seo) Menggunakan Metode White Hat Seo Untuk Meningkatkan Peringkat Dan Trafik Kunjungan Website," SNATIF, vol. 978-602-11, pp. 269-276, 2017.

[12] M. K. Mittal, N. Kirar, and J. Meena, "Implementation of Search Engine Optimization: Through White Hat Techniques," Proc. - IEEE 2018 Int. Conf. Adv. Comput. Commun. Control Networking, ICACCCN 2018, vol. 5, no. 2, pp. 674-678, 2018. 